\title{
Single-nucleotide Polymorphisms of AGT, SOD2, CAT in Risk Estimates for Arterial Hypertension among Young People
}

\author{
A. V. Kovaleva, I. V. Astratenkova, N. E. Golovanova, \\ O. G. Orlova, O. V. Rybalchenko \\ St. Petersburg State University, \\ 7-9, Universitetskaya nab., St. Petersburg, 199034, Russian Federation
}

For citation: Kovaleva A.V., Astratenkova I. V., Golovanova N.E., Orlova O. G., Rybalchenko O.V. Single-nucleotide Polymorphisms of AGT, SOD2, CAT in Risk Estimates for Arterial Hypertension among Young People. Vestnik of Saint Petersburg University. Medicine, 2019, vol. 14, issue 2, pp. 141146. https://doi.org/10.21638/spbu11.2019.206

\begin{abstract}
Arterial hypertension is one of the most common cardiovascular diseases and one of the main causes of mortality and disability of population. Opportunity to predict emergence of arterial hypertension and to take preventive measures in pre-nosological diagnostics of disease arouse research interest in this issue. Possibility to predict progression of arterial hypertension based on polymorphic variants of $A G T$ gene (C521T, rs4762) identification, which encodes angiotensinogen protein in combination with polymorphic variants of CAT (-262C/T, rs1001179), encoding catalase, and polymorphic variants of SOD2 (C47T, rs4880), encoding mitochondrial superoxide dismutase, are discussed in this article. Decrease of antioxidant enzymes (catalase and superoxide dismutase) activity leads to accumulation of reactive oxygen species in cells. They may activate NF-kB transcription factor, which increases expression of individual genes involved in sodium homeostasis and in blood pressure control, including angiotensinogen. Increased angiotensinogen concentration in blood constitutes a risk factor in arterial hypertension development. In our opinion, combination of polymorphic variants of AGT, CAT and SOD genes expands the possibilities of personalized medicine.Performed investigation involved 65 medical students of St Petersburg State University. DNA was extracted from epithelial cells of the oral cavity. Genotyping of DNA samples was determined by real-time PCR. Obtained results of our investigation enabled to reveal $A G T$ genotypes associated with hypertension in 12 students. The article discusses combinations of TT and CT genotypes of AGT with unfavorable alleles of antioxidant enzymes.Carriers of heterozygous SOD2 genotype and homozygous CC genotype $C A T$ are in more unfavorable conditions compared to carriers of the CC genotype SOD2 and CT genotype CAT, as SOD2 is a key antioxidant enzyme protecting from ROS.
\end{abstract}

Keywords: arterial hypertension, genetic polymorphism, angiotensinogen, superoxide dismutase, catalase.

\section{Introduction}

Modern personalized medicine assumes development of basic methods of diseases prevention and control based on the knowledge of the individual characteristics. Such individual characteristics include patient genome and epigenome information. Identification of genetic predisposition is important for the multifactorial diseases prevention since

(c) Санкт-Петербургский государственный университет, 2019 


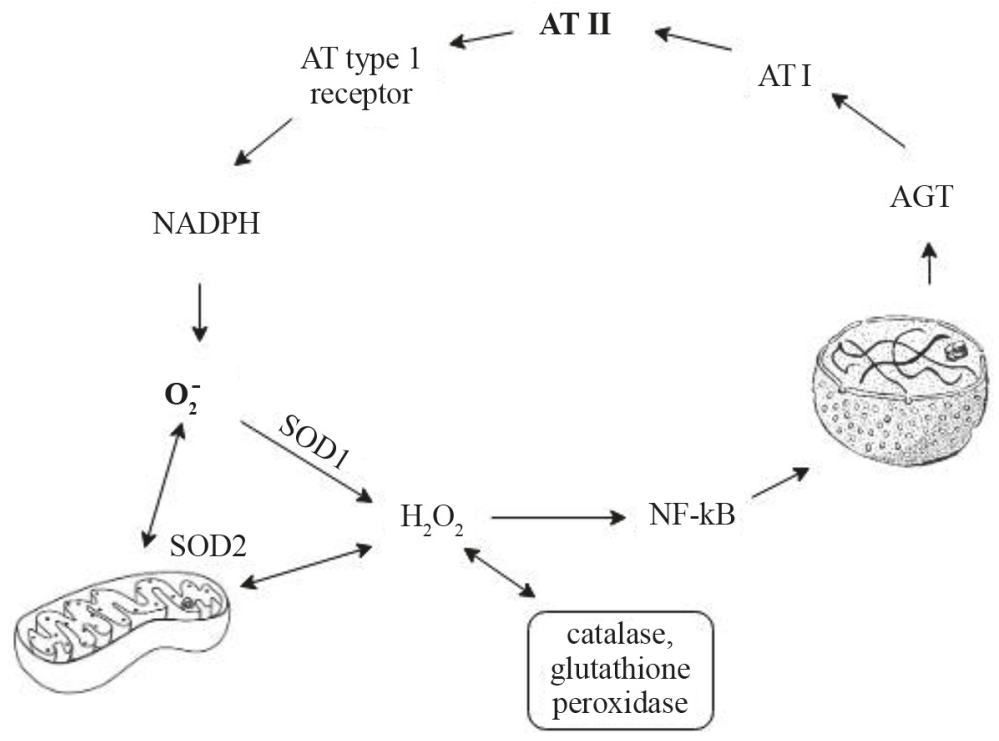

Fig. 1. RAS and antioxidant system enzymes in blood pressure regulation

disease manifestation depends on person's lifestyle, diet, physical activities, rest regime, sleep duration, etc.

Cardiovascular diseases (CVD) are multifactorial ones for which genetic determination was proven. Numerous studies of the cardiovascular pathology, demonstrate that $20-60 \%$ of blood pressure changes are genetically determined. Thus arterial hypertension $(\mathrm{AH})$ is associated with gene polymorphisms of angiotensinogen, $\beta 1$-adrenergic receptor, cytochrome P450 $[1 ; 2 ; 3]$.

Arterial hypertension as increased stressful conditions risk, lack or excessive physical activity risk, consumption of junk food, smoking, and alcohol abuse risks are widely spread in highly developed countries. It is well known that multifactor diseases are associated with the development and activation of oxidative stress, which can be caused by decrease in antioxidant defense effectiveness. Arterial hypertension and ischemic heart disease can trigger acute myocardial infarction and further development of heart failure. One of the mechanisms developing such pathologies is mitochondrial dysfunction associated with disruption of antioxidant system enzymes. Antioxidant enzymes are widely represented in the body cells. So, superoxide dismutase (SOD) catalyses superoxide radical breakdown in the mitochondria and cytoplasm, catalase (CAT) decomposes $\mathrm{H}_{2} \mathrm{O}_{2}$ at high concentrations in the cytoplasm.

It is well known that angiotensin II (Ang II) activates NADPH oxidase in blood vessels, kidneys, brain, increasing superoxide radical and $\mathrm{H}_{2} \mathrm{O}_{2}$ formation [4; 5]. Modern studies demonstrate that $\mathrm{H}_{2} \mathrm{O}_{2}$ plays a role of paracrine mediator of cardiovascular and renal dysfunctions. Therefore, $\mathrm{H}_{2} \mathrm{O}_{2}$ activates the nuclear factor NF-kB which increases genes expression involved in sodium homeostasis and blood pressure control, including angiotensinogen gene (Fig. 1). T. Sousa and co-authors demonstrated that increase in the $\mathrm{H}_{2} \mathrm{O}_{2}$ level is directly involved in the angiotensin-II-induced hypertension development and intrarenal activation of renin-angiotensin system (RAS) [5]. Accordingly, concen- 
trations of $\mathrm{H}_{2} \mathrm{O}_{2}$ and angiotensinogen (AGT) are interdependent. Increased blood AGT concentration and decreased activity of SOD and CAT lead to accumulation of reactive oxygen species (ROS) in cells and further development of mitochondrial dysfunction.

This investigation aims to assess young people's predisposition to hypertension based on determination of the polymorphism C521T of the AGT gene, polymorphisms $-262 \mathrm{C} / \mathrm{T}$ of the CAT gene and C47T gene of the SOD2.

\section{Methods}

The study involved 65 medical students of St Petersburg State University (18-22 years old) who have no cardiovascular pathology. DNA was isolated from oral epithelial cells using commercial DNA-sorb-A kits (InterLabService, Moscow). Genotyping of DNA samples was carried out using Sintol's real-time PCR reagent (Moscow). Gene polymorphisms were determined using "DTlite - DNA technology".

$A G T$ gene polymorphism (C521T, rs4762), encoding an angiotensinogen protein, was determined in the group of students examined. Then, genetic polymorphisms of CAT gene (-262C/T, rs1001179), encoding catalase, and SOD2 gene (C47T, rs4880), encoding mitochondrial superoxide dismutase, were identified in carriers of the T AGT allele.

\section{Results and discussion}

The study results of the C521T polymorphism frequency of the AGT gene in students group are presented in Fig. 2. Obtained results distributed as follows: $\mathrm{CC}-53$ persons, $\mathrm{CT}-8$ persons, $\mathrm{TT}-4$ persons. Rates of alleles occurrence: $\mathrm{C}-87.7 \%, \mathrm{~T}-12.3 \%$.

Distribution of CAT $(-262 \mathrm{C} / \mathrm{T})$ genotypes and SOD2 (C47T) genes among polymorphic variants of $A G T$ (C521T) gene is presented in Fig. 3. In the group of CT AGT genotype carriers, two students had CC genotype of CAT and six - CT; two students had CC genotype of SOD2 and six - CT. There was one CC and three CT genotype carriers of $C A T$, one CC and three CT genotype carriers of the SOD2 in TT genotype carriers of AGT.

Polymorphic variant (C521T) of $A G T$ is characterized by replacement of cytosine (C) by thymine (T) at position 521 of gens. It leads to replacement of tryptophan by methionine at position 174 of amino acid sequence (Thr174Met). Presence of T allele is associated with increased risk for hypertension [6]. Therefore, TT genotype of the AGT gene seems to be the most clinically significant for risk assessment for cardiovascular pathology. This genotype is associated with blood angiotensinogen elevation, which is responsible for increased production of angiotensin II and activation of ROS. At the same time, the role of SOD2 and catalase increases.

Structural variability of the SOD2 gene affects amount and activity of the Mn-dependent superoxide dismutase, synthesized in cells. C47T polymorphism leads to replacement of alanine (Ala) by valine (Val) amino acid, modifies secondary protein structure, alters mitochondrial targeting sequence and can affect the enzyme transfer from the cytoplasm to the mitochondrial matrix. It was found out that the enzyme activity in mitochondria is decreased by $30-40 \%$ and the risk of developing cardiovascular pathology is elevated in $\mathrm{T}$ allele carriers [7].

$C A T-262 \mathrm{C} / \mathrm{T}$ polymorphism is a single nucleotide substitution of cytosine (C) to thymine $(\mathrm{T})$ in promoter region at position 262. It is known that CC genotype carriers 


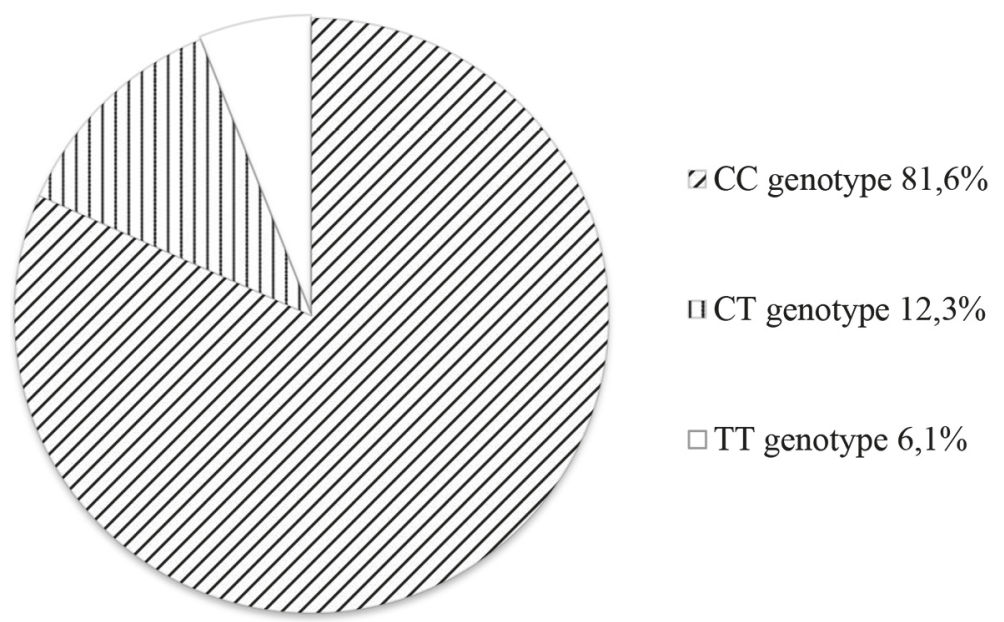

Fig. 2. The genotype distribution of the AGT C521T

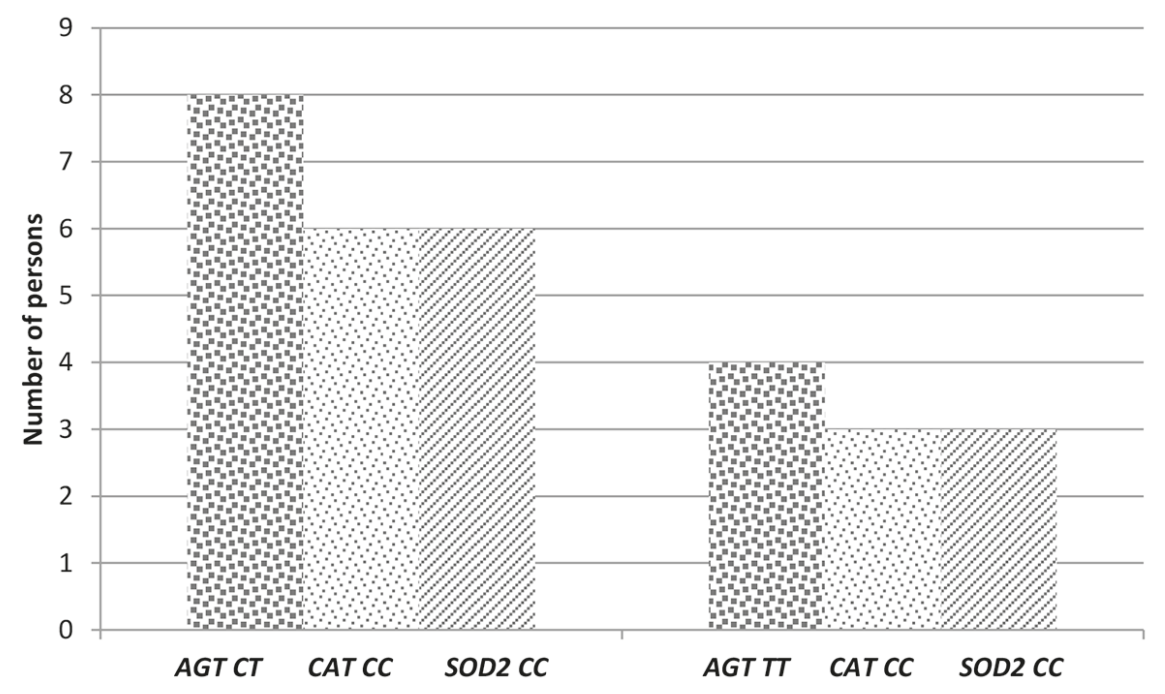

Fig. 3. The distribution of genotypes of CAT (-262C/T) and SOD2 (C47T) genes among the polymorphic variants of the AGT (C521T) gene

have a higher catalase enzyme activity than CT and TT genotypes carriers. Thereby $\mathrm{C}$ allele increases the antioxidant status of cells and consequently reduces the risk of cardiovascular diseases. However, nowadays there is no proof that the $\mathrm{T}$ allele correlates with cardiovascular pathology and with risk of arterial hypertension [8].

According to our study results, $A G T$ genotypes associated with hypertension were identified in 12 students (Table). However, student No. 58 had SOD2 and CAT genotypes that indicate a normal level of antioxidant system enzymes. This might indicate that cells are well protected when oxidative processes are activated by Ang II. Students No. 2, 9, 11, 28,38 are heterozygous carriers of all studied genotypes and, therefore, have a moderate risk of developing hypertension due to increased concentration of Ang II and decreas- 
ing SOD2 and CAT activity. There are carriers of the heterozygous genotype SOD2 and homozygous CC genotype CAT in more adverse conditions compared to carriers of the CC genotype SOD2 and CT genotype CAT, as SOD2 is a key antioxidant enzyme in the defense against oxidative stress. We assume that the risk of developing hypertension is decreased among the students No. 42, 61, 12, 67. In our opinion, students No. 49 and 66 that carried 4 unfavorable alleles of the studied genes have the greatest risk of developing hypertension.

Table. The SOD2 and CAT genotypes distribution among the students with CT and TT genotypes of the $A G T$

\begin{tabular}{|c|c|c|c|c|c|}
\hline $\begin{array}{c}A G T \\
\text { CT }\end{array}$ & SOD2 & CAT & $\begin{array}{c}\text { AGT } \\
\text { TT }\end{array}$ & SOD2 & CAT \\
\hline No. 2 & CT & CT & No. 42 & CT & CC \\
\hline No. 9 & CT & CT & No. 49 & CT & CT \\
\hline No. 11 & CT & CT & No. 61 & CC & CT \\
\hline No. 12 & CT & CC & No. 66 & CT & CT \\
\hline No. 28 & CT & CT & & & \\
\hline No. 38 & CT & CT & & & \\
\hline No. 58 & CC & CC & & & \\
\hline No. 67 & CC & CT & & & \\
\hline
\end{tabular}

It is necessary to consider that lifestyle of medical student is rather stressful and further doctor's work is accompanied by high level of stressful situations, therefore, a significant number of risk factors can lead to early development of arterial hypertension. Methods of assessing genetic predisposition to multifactorial diseases are the basis of personalized medicine and should be used for an early individual disease prevention.

\section{References}

1. Bulgakova I. V., Bushueva O.Y., Polonikov A.V. Polymorphism a154c of cyp1a2 gene and risk of development of essential hypertension. Analyse of assosiation and relations with environmental risk factors. Fundamental research, 2013, iss. 9, pp. 994-998. (In Russian)

2. Timasheva Ya. R., Nasibullin T. R., Imaeva E. V., Mirsaeva G. Kh., Mustafina O.E. Beta-adrenoreceptor gene polymorphisms and the risk of essential hypertension. Arterial'naya gipertenziya, 2015, vol. 21, iss. 3, pp. 259-266. https://doi.org/10.18705/1607-419X-2015-21-3-259-266 (In Russian)

3. Malyutina S.K., Maksimov V.N., Orlov P.S., Mazdorova E.V., Ryabikov A.N., Nikitin Yu. P., Voevoda M.I. The association of blood pressure and hypertension with genetic markers identified in genome-wide association studies. Russian Journal of Cardiology, 2018, vol. 23, iss. 10, pp. 8-13. https:// doi.org/10.15829/1560-4071-2018-10-8-13 (In Russian)

4. Obrezan A. G., Kulikov N. V. Neuro-humoral disbalance in chronic heart failure: classic and modern perspectives. Russian Journal of Cardiology, 2017, iss. 9, pp. 83-92. https://doi.org/10.15829/15604071-2017-9-83-92 (In Russian)

5. Sousa T., Oliveira S., Afonso J., Morato M., Patinha D., Fraga S., Carvalho F., Albino-Teixeira A. Role of $\mathrm{H} 2 \mathrm{O} 2$ in hypertension, renin-angiotensin system activation and renal medullary disfunction caused by angiotensin II. British journal of Pharmocology, 2012, vol. 166, iss. 8, pp. 2386-2401. https://doi. org/10.1111/j.1476-5381.2012.01957.x 
6. Wei Gu, Jielin Liu, Qiuli Niu, Hao Wang, Yuqing Lou, Kuo Liu, Lijuan Wang, Zuoguang Wang, Jingmei Zhang, Shaojun Wen. A-6G and A-20C Polymorphisms in the Angiotensinogen Promoter and Hypertension Risk in Chinese: A Meta-Analysis. PLoS One, 2011, vol. 6, iss. 12. https://doi. org/10.1371/journal.pone.0029489

7. Podolskaya A. A., Galyavich A. S., Maikova E. V., Kravtsova O. A., Alimova F. K. The role of antioxidant system genes in the formation of coronary heart disease clinical phenotypes. Kazan Medical Journal, 2013, vol. 94, iss. 2, pp. 228-234. (In Russian)

8. Zhou X., Cui J., DeStefano A.L., Chazaro I., Farrer L. A., Manolis A. J., Gavras H., Baldwin C.T. Polymorphisms in the promoter region of catalase gene and essential hypertension. Disease Markers, 2005, vol. 21, iss. 1, pp. 3-7. https://doi.org/10.1155/2005/487014

Received: April 29, 2019 Accepted: June 17, 2019

Authors' information:

Alexandra V. Kovaleva — student; 9xaasaax9@gmail.com

Irina V. Astratenkova — PhD, Associate Professor; astratenkova@mail.ru

Natalya E. Golovanova - PhD, Associate Professor; nesh1764@mail.ru

Olga G. Orlova - PhD, Associate Professor; st003724@spbu.ru

Oksana V.Rybalchenko - Dr. Sci., Professor; ovr@inbox.ru 